\title{
Role of Common Primer as an Antifungal Agent in Timber
}

\author{
Arghyadeep Bhattacharjee ${ }^{1 *}$, Maitrayee Mondal ${ }^{1}$, Krishanu Dutta $^{1}$, \\ Krittika Rao ${ }^{1}$ \\ Monmita Bhar ${ }^{2}$, Nafizul Haque Kazi ${ }^{2}$, Aritra Dutta ${ }^{2}$, Vinayak Ghosh ${ }^{2}$ \\ Dr. Arup Kumar Mitra ${ }^{3}$ \\ I'Post Graduate Department of Microbiology, St. Xavier's College, Kolkata, Affiliated to Calcutta University, \\ India) \\ ${ }^{2}$ (Undergraduate Department of Microbiology, St. Xavier's College, Kolkata, Affiliated to Calcutta University, \\ India) \\ ${ }^{3}$ (Associate Professor, Department of Microbiology, St. Xavier's College, Kolkata, Affiliated to Calcutta
} University, India)

\begin{abstract}
Wood, one of the most abundant raw materials in the world used by the human society for industrial products and energy, is the secondary xylem of vascular plants. Wood is typically composed of about 25\% lignin, $70 \%$ cellulosic carbohydrates, with roughly $45 \%$ cellulose and $25 \%$ hemicelluloses. Lignin is a complex phenolic polymer that provides mechanical strength to the trees. Lignin's physical and chemical properties also serve as a barrier against the invasion of pests and pathogens. But some microorganisms are capable of lignin degradation, which comes as one of the biggest threats. These include bacteria as well as fungi. So methods of protecting wood from these microbes are being looked for; Ex-coating wood with chemical preservers like primers or wax, staining wood. In this study, an infected Pinewood sample was chosen. Isolation of fungus from infected part of the wood on PDA and its microscopic characterization showed one-four celled conidia like branched chain structures that resembled Cladosporium. Each cell measured approximately 6 to $8 \mu \mathrm{m}$. Soil jar method under stationary condition at $37^{\circ} \mathrm{C}$ over a time of 6 weeks helped in detecting its biodegradative ability for fresh Shorea robusta wood. A prominent reduction in the weight of fresh wood infected with isolates was found that confirmed the wood degrading ability of isolate. This method was repeated for same wood sample coated with primer using same isolate that confirmed the primer degrading ability of the isolate. Biodegradative enzyme assays of the isolate was carried out using veratryl alcohol, indicated presence of lignin peroxidase which could possibly contribute to its wood degrading ability. The isolates not only have a ligninolytic activity but also have a cellulolytic (endoglucanase) activity. Thus primers are susceptible to microbial degradation and cannot be used as a protectant of wood and alternatives should be searched for. While these primers when used on other substrates, after use, can be bio-remediated using this isolate.
\end{abstract}

Keywords: fungi, hemicellulose, endoglucanase, primers, xylem, wax

\section{Introduction}

Wood has a long history of being used as fuel, which continues to this day, mostly in rural areas of the world. New domestic housing in many parts of the world today is commonly made from timber-framed construction. Wood has always been used extensively for furniture. Further developments include new lignin glue applications, recyclable food packaging, rubber tire replacement applications, anti-bacterial medical agents, and manufacture of high strength fabrics or composites. Wood and other lignocellulosic materials are formed from three main polymeric constituents: cellulose, lignin, and hemicelluloses. But a major threat is that wood is decomposed by a variety of biological agents, including fungi, bacteria, and insects. Wood-destroying fungi are the most frequent biodegrading agents of logs, timber and wood products. Rotten wood has a lower density, worse mechanical properties and its physical properties are changed individually according to the kind of rot (brown, white or soft). Fungi colonize wood and degrade cell wall components to form brown, soft, or white rot. Brown-rot fungi, which degrade primarily the polysaccharide components of wood, leave a lignin framework. White-rot fungi may degrade all cell wall components [1]. The chemical composition (including environmental factors such as the water activity, temperature and type of medium) and the physical structure (i.e. the distribution of tracheids and pits) of the resource determine the penetration behaviour of a wood-decay fungus. Soil jar method is used to determine the rate of fungal wood degradation [2]. Ceriporiopsis subvermispora is one of the best examples of a selective lignin degrader produces oxidative enzymes during wood biodegradation. Mn-dependent peroxidase (MnP) is the pre- dominant enzyme, followed by laccase. Endoglucanase is important in cellulose decomposition as it hydrolyzes glucosidal linkages, gradually splitting away glucosidal residuals and resulting in reduced sugar formation [3]. 
Wood-inhabiting fungi, not necessarily responsible for major decay, are shown to be capable of degrading a toxic compound into a less potent form, thus rendering it less effective in protecting wood from decay by less-tolerant basidiomycetous wood-destroyers. Sweetgum or pine sapwood blocks treated with preservatives (ammoniacalcopper arsenate, fluor-chrome-arsenate dinitrophenol, a creosote or pentachlorophenol) were exposed progressively to two different wood-inhabiting fungi with sterilization between the first and second exposure. The first fungus rendered the preservative ineffective but without appreciably decaying the wood itself. Chemical analyses of treated blocks indicated that in the first exposure, the fungi had substantially depleted sodium arsenate and pentachlorophenol. Lyret.al (1963) showed that wooddestroying basidiomycetes that secrete laccase into the culture medium are able to overcome the toxic effects of pentachlorophenol. Creosote, one of the oldest wood preservatives is a most potent fungicide of complex composition, containing phenols, aromatic hydrocarbons, nitrogen bases, and other toxicants. Marsden (1951, 1954) suggested that, over long periods of time, this fungus may actually degrade the preservative value since creosote may serve as its sole source of nitrogen and carbon. Due to the unspecificity of ligninolytic extracellular enzymes (phenoloxidases) some of fungi can degrade not only lignin but some aromatic compounds that are used in wood protection (e.g. pentachlorophenol) as well [4].

In this study, a fungus was isolated from infected pinewood and its ability to infect fresh wood of Shorea robusta (Indian Sal tree) was detected. Bio-degradative enzyme assay of the isolate was carried out to detect the presence of wood degrading enzymes like lignin peroxidise, Endoglucanase. White primers containing lead was subjected to fungal growth in order to check the ability of the isolate to degrade the commercially available primers. The study was undertaken to gain insight about the efficiency of Common primer as an antifungal agent in timber.

\subsection{Collection and Characterization of the wood sample}

\section{Materials And Methods}

Wood samples were collected from Kurseong in the district of Darjeeling. The infected wood samples were collected in sterile containers. Collected samples were transferred to the laboratory under sterile condition for analysis. The collected samples are analysed and its physical (weight, colour, texture) properties were noted.

\subsection{Isolation \& characterization of the microorganisms}

Infected portions of the collected wood samples were taken and surface sterilization was done with $0.1 \%$ Mercuric chloride $\left(\mathrm{HgCl}_{2}\right)$.These parts were inoculated in the PDA (Potato Dextrose Agar) slant. The slants were incubated for 7 days at around $30^{\circ} \mathrm{C}$. After observation of growth, selected colony was inoculated for pure culture by streaking. Both Gram staining and Lactophenol cotton blue staining were done for characterizations and microscopic observation of the organism.

\subsection{Determination of the ligninolytic activity of the microorganism}

Lignin Peroxidases (LiP) activity [5] was measured as the oxidation of veratryl alcohol (VA) to veratryl aldehyde with an increased absorbance at $310 \mathrm{~nm}$. Reaction mixtures contained $50 \mathrm{mM}$ sodium tartarate buffer, $\mathrm{pH} 2.5,0.08 \mathrm{M}$ veratryl Alcohol, $200 \mu \mathrm{l}$ samples and $500 \mu \mathrm{M} \mathrm{H}_{2} \mathrm{O}_{2}$ [6]. Reaction was initiated by the addition of $\mathrm{H}_{2} \mathrm{O}_{2}$. One unit activity was defined as the amount of enzyme oxidizing $1 \mu \mathrm{mol}$ of substrate per minute.

\subsection{Determination of cellulolytic activity of the isolate}

Fungal cellulolytic ability [6] was evaluated by primary estimation of their endoglucanase (EC 3.2.1.4, CMcellulase) activity. This enzyme is important in cellulose decomposition as it hydrolyzes glucosidal linkages, gradually splitting away glucosidal residuals and resulting in reduced sugar formation. Fungal isolates were cultivated on modified Czapek medium: $\mathrm{NaNO}_{3}-2 \mathrm{~g} ; \mathrm{KH}_{2} \mathrm{PO} 4-1 \mathrm{~g} ; \mathrm{MgSO}_{4} \cdot 7 \mathrm{H}_{2} \mathrm{O}-0.5 \mathrm{~g} ; \mathrm{KCl}-0.5 \mathrm{~g}$; $\mathrm{FeSO}_{4}-0.01 \mathrm{~g}$, carboxymethyl cellulose $-10 \mathrm{~g}$; agar $-20 \mathrm{~g} ; \mathrm{H}_{2} \mathrm{O}-1000 \mathrm{ml}$, at $24{ }^{\circ} \mathrm{C} \pm 2{ }^{\circ} \mathrm{C}$ temperature for 5 days. The endoglucanase activity was detected by flooding of the $0.1 \%$ aqueous solution of Congo red and it revealed by a pale orange zone around the colony. The activity was evaluated by the width $(\mathrm{mm})$ of this zone.

\subsection{Estimation of Wood degradation ability by Soil Jar experiment}

This experimental method was done to analyse the ability to degrade wood by the isolated microorganism. The same methods were carried out twice, one for normal wood sample and another for the wood painted with primer. To compare the rate of wood degradation in Pinus sabiniana in case of an unaffected piece of wood and a primer-coated unaffected piece of wood, when both are sprayed with a spore suspension of isolated fungi. 


\subsubsection{Preparation of spore suspension}

The spores of isolated fungus were taken in a tube containing sterile water from pure culture. The solution was mixed and filtration was done. The filtrate was then taken in sprayer for spraying in wood. The whole procedure was strictly done in sterile condition.

\subsubsection{Soil jar method}

The unaffected wood blocks were taken and dried in hot air oven for removing moisture from the blocks. The blocks were placed into glass conicals containing 50 grams of soil in each after taking their dry weight. 3 sets of experiments were done. In the first set, there was a control, containing only soil and wood block. In second set spore suspension was sprayed on wood. And in the third set, same spore suspension was spread on both soil surface and wood blocks. All the 3 conical flasks were kept in fungal incubator for 7, 14 \& 21 days and their weight were taken.

\subsubsection{Determination of wood degradation ability of the microorganism by Soil Jar method in presence of} Primer

Primer is a coating applied to a surface to prepare it for paint or another coating or adhesive. It is made with $20 \%-30 \%$ synthetic resin, $60 \%-80 \%$ solvent and $2 \%-5 \%$ additive agent. Some primer contains polyethylene (plastic), for better durability. Primer is a paint product that allows finishing paint to adhere much better than if it was used alone. It is used usually to protect furniture made out of wood from degradation.

In this set of experiments, 3 wood blocks were painted with primer and dried. The blocks were placed into glass conicals containing 50 grams of soil in each after taking their dry weight .One as control, containing only soil and wood block. In second set spore suspension was sprayed on wood. And in the third set, same spore suspension was spread on both soil surface and wood blocks. All the 3 conical flasks were kept in fungal incubator for 7, $14 \& 21$ days and their weight were taken.

\section{Results}

3.1. Physical and chemical characterization of the wood sample The physical characteristics of the sample are given below (Table 1).

Table 1: Physical characteristics of the collected sample

\begin{tabular}{|c|c|c|}
\hline Physical Properties & Control (Unaffected sample) & Test (Infected Sample) \\
\hline Weight & $11.9 \mathrm{gm}$ & 10.22 \\
\hline Colour & Yellowish & Greyish Brown \\
\hline Texture & Smooth & Rough \\
\hline
\end{tabular}

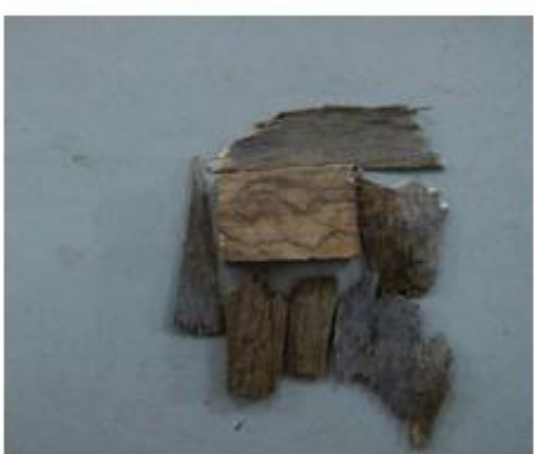

(A)

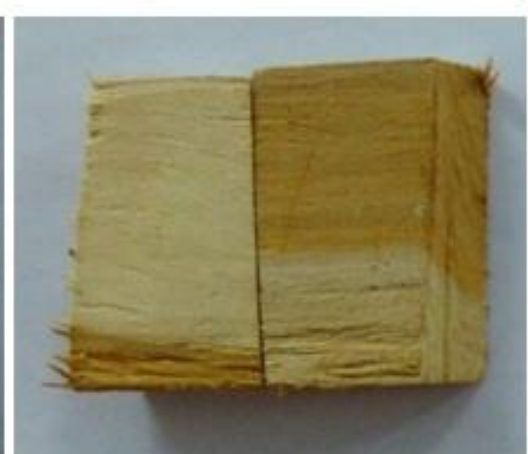

(B)

Figure 1: The wood samples obtained from Kurseong. (A) Infected and (B) Unaffected

\subsection{Isolation, Identification and Characterization of the microorganisms}

Mostly olive brown to blackish-brown coloured, powdery colony due to the abundant production of conidia was observed after 8 days of incubation in the PDA slant. Lactophenol cotton blue staining showed the presence of shield-shaped conidia, a distinct hilum, and chains of conidia that readily disarticulate. These colonies are identified as the fungi Cladosporium sp. 

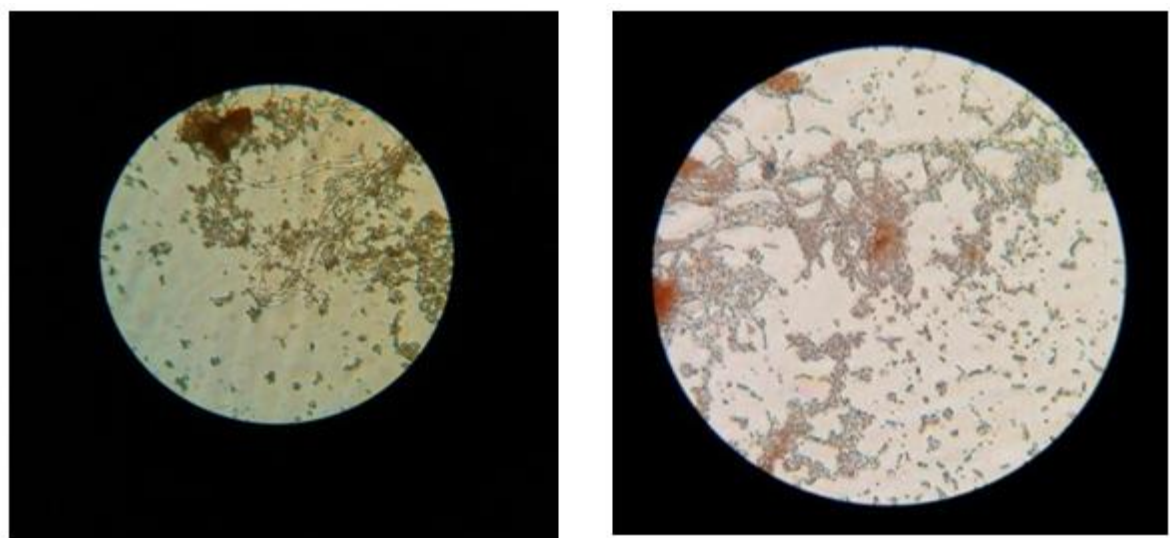

Figure 2: Microscopic view of the spores of Cladosporium $s p$ at $45 \mathrm{X}$ and 100X. Olive brown to blackish-brown coloured, powdery colony was observed. Lactophenol cotton blue staining showed the presence of shieldshaped conidia, a distinct hilum, and chains of conidia.

\subsubsection{Measurement of the spores of Cladosporium by Micrometry.}

Size of the spores of Cladosporium sp obtained by micrometry analysis from PDA slant is found to be $8.84 \mu \mathrm{m}$
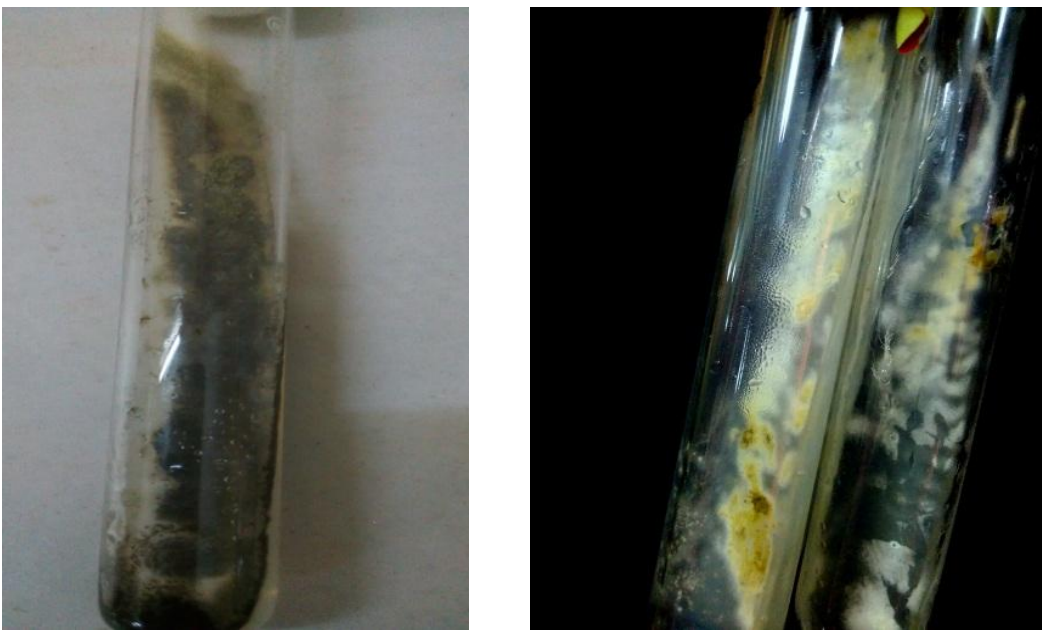

Figure 3: Figure showing the pure culture of Cladosporium sp. in PDA slant. Green round shaped spores are observed.

3.3 Determination of the ligninolytic activity of the fungus by Lignin Peroxidase Assay.

The lignin peroxidase assay was performed and optical density was measured at $310 \mathrm{~nm}$

Table 2: Optical density of the isolates at $310 \mathrm{~nm}$ for lignin peroxidise assay

\begin{tabular}{|c|c|c|}
\hline Isolates & Control & O.D at 310nm \\
\hline Cladosporium spp. 1 & 0.337 & 0.295 \\
\hline Cladrosporium spp. 2 & 0.337 & 0.302 \\
\hline
\end{tabular}

Table 3: Ligninolytic activity of the fungal isolate

\begin{tabular}{|c|c|}
\hline Isolates & $\begin{array}{l}\text { Concentration of the degraded Veratryl Alcohol } \\
\text { per ml of the crude enzyme }\end{array}$ \\
\hline Cladosporium spp. 1 & $0.010 \mathrm{M}$ \\
\hline Cladosporium spp. 2 & $0.009 \mathrm{M}$ \\
\hline
\end{tabular}




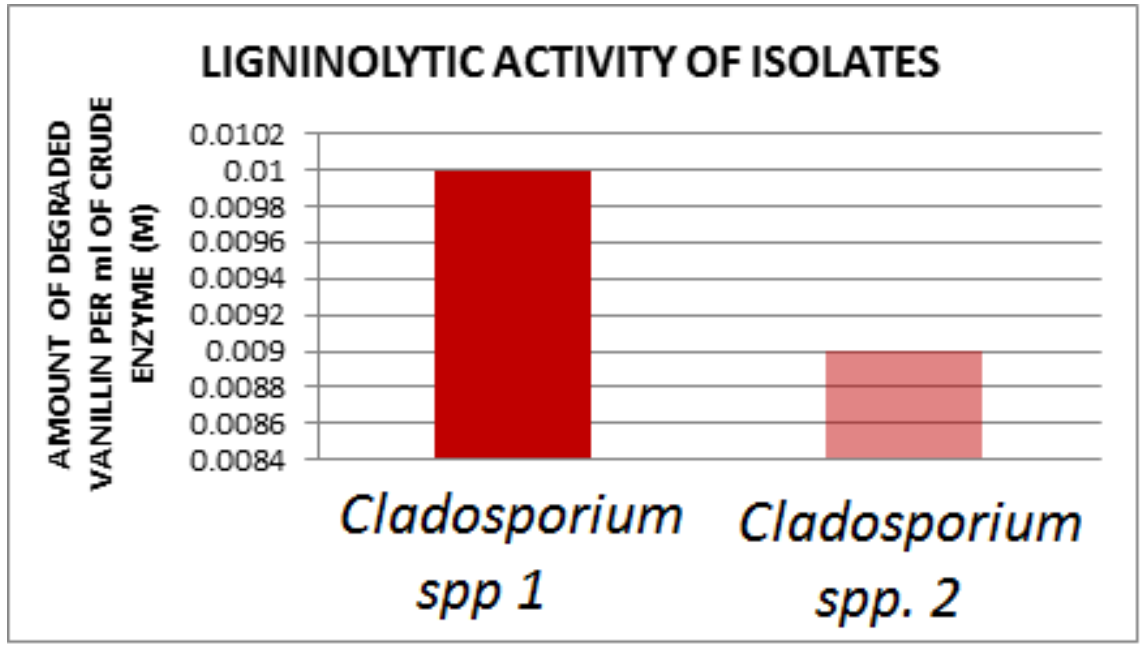

Figure 4: Graphical representation demonstrating the ligninolytic activity of the fungal isolates. Highest ligninolytic activity has been found in Cladosporium spp. 1

\subsection{Determination of the cellulolytic activity of the fungal isolates}

The Endoglucanase activity was detected by flooding of the $0.1 \%$ aqueous solution of Congo red and it revealed by a pale orange zone around the colony. The activity was evaluated by the width (mm) of this zone.

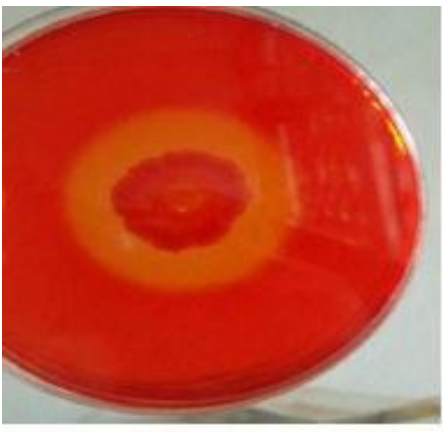

Isolate 1

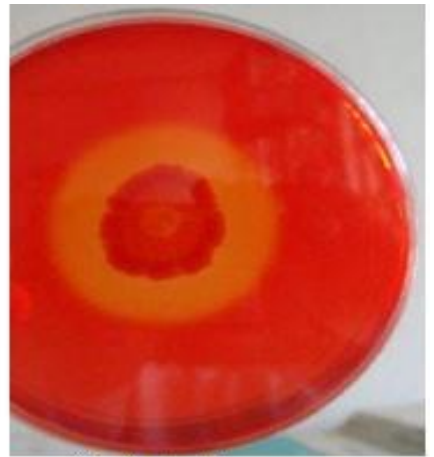

Isolate 2

Figure 5: The strains of isolated Cladosporium spp. showed Endoglucanase activity by revealing a pale orange colour zone around the colony on PDA plate flooded with Congo red.

Table 4: Width of the zone $(\mathrm{mm})$ formed around fungal colony on PDA plate

\begin{tabular}{|c|c|}
\hline Designation of the fungal isolates & Width of the zone (mm) \\
\hline Cladosporium spp.1 & 11.25 \\
\hline Cladosporium spp.2 & 9.68 \\
\hline
\end{tabular}

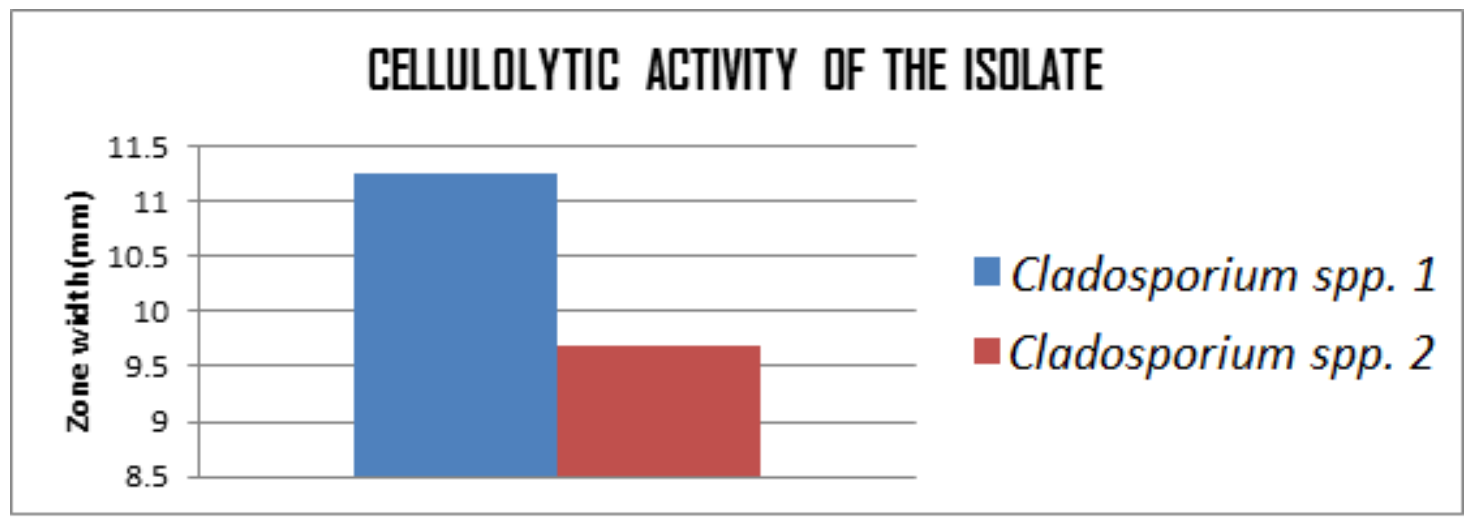

Figure 6: Graphical representation showing endoglucanase activity of the fungal isolates. Highest cellulolytic activity was found in Cladosporium spp. 1 


\subsection{Determination of the wood degradation activity of the isolated fungus by Soil Jar method}

From the soil-jar experiment it was observed that in both the cases there is a loss in weight of the wood block that is both in case of simple unaffected wood block and wood block coated with primer. Therefore, it can be concluded that primer, though being used very commonly as a protective measure against wood degradation is not completely effective in protecting wood from environmental and biological hazards as degradation of wood was observed in both the cases though the loss in weight of primer-coated wood as compared to the other was much less.

Table 5: Degradation of wood in absence of Primer

\begin{tabular}{|c|c|c|}
\hline \multirow{2}{*}{ Experiment set no. } & \multicolumn{2}{|c|}{$\begin{array}{c}\text { Weight of wood block after spraying with } \\
\text { spore suspension }\end{array}$} \\
\cline { 2 - 3 } & Initial (gm) & Final (gm) \\
\hline Set 1 & 2.987 & 2.707 \\
\hline Set 2 & 3.717 & 3.037 \\
\hline Set 3 & 4.086 & 2.926 \\
\hline
\end{tabular}

Table 6: Degradation of wood in presence of Primer

\begin{tabular}{|c|c|c|}
\hline \multirow[t]{2}{*}{ Experiment Set no. } & \multicolumn{2}{|c|}{$\begin{array}{l}\text { Weight of the wood block after spraying with } \\
\text { spore suspension }\end{array}$} \\
\hline & Initial (gm) & Final (gm) \\
\hline Set 1 & 11.90 & 11.88 \\
\hline Set 2 & 12.0 & 11.53 \\
\hline Set 3 & 10.96 & 10.48 \\
\hline
\end{tabular}

Table 7: Amount of wood degraded in absence of Primer

\begin{tabular}{|c|c|}
\hline Experiment Set no. & Amount of wood degraded(gm) \\
\hline Set 1 & 0.28 \\
\hline Set 2 & 0.68 \\
\hline Set 3 & 1.16 \\
\hline
\end{tabular}

Table 8: Amount of wood degraded in presence of Primer

\begin{tabular}{|c|c|}
\hline Experiment Set no. & Amount of wood degraded(gm) \\
\hline Set 1 & 0.02 \\
\hline Set 2 & 0.47 \\
\hline Set 3 & 0.48 \\
\hline
\end{tabular}

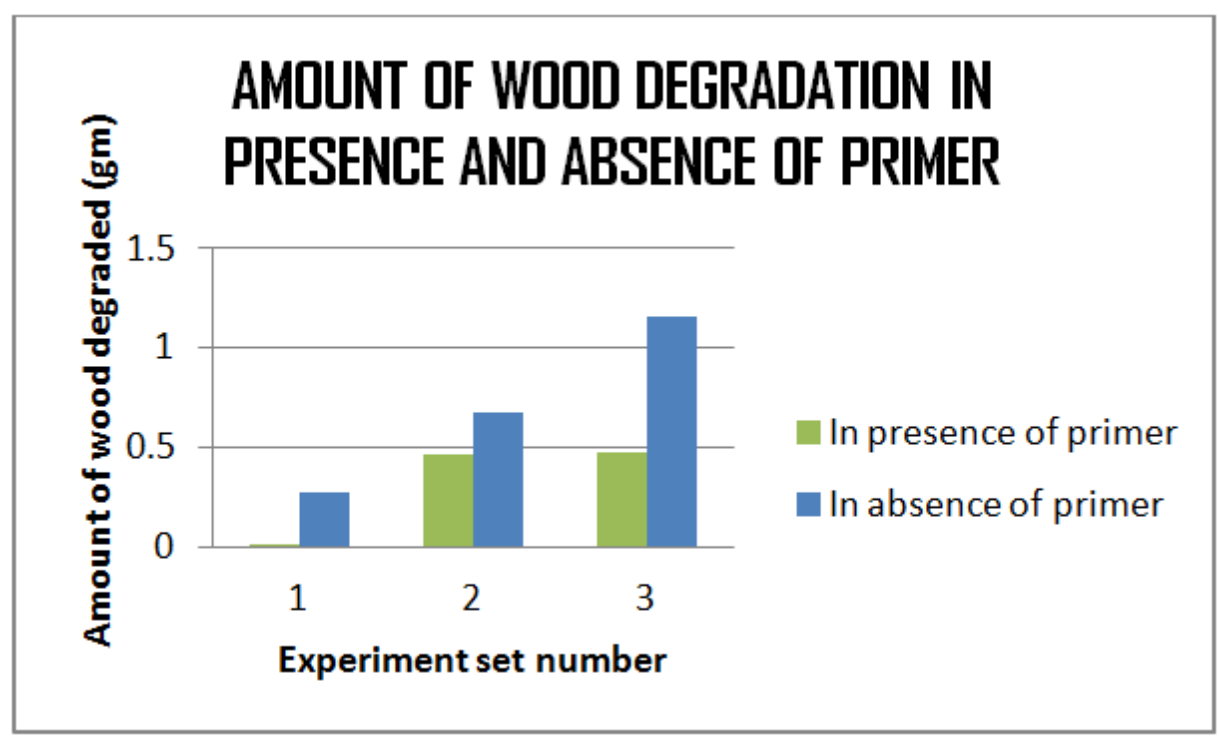

Figure 7: Graphical representation showing the amont of wood degraded in presence and absence of primer. 

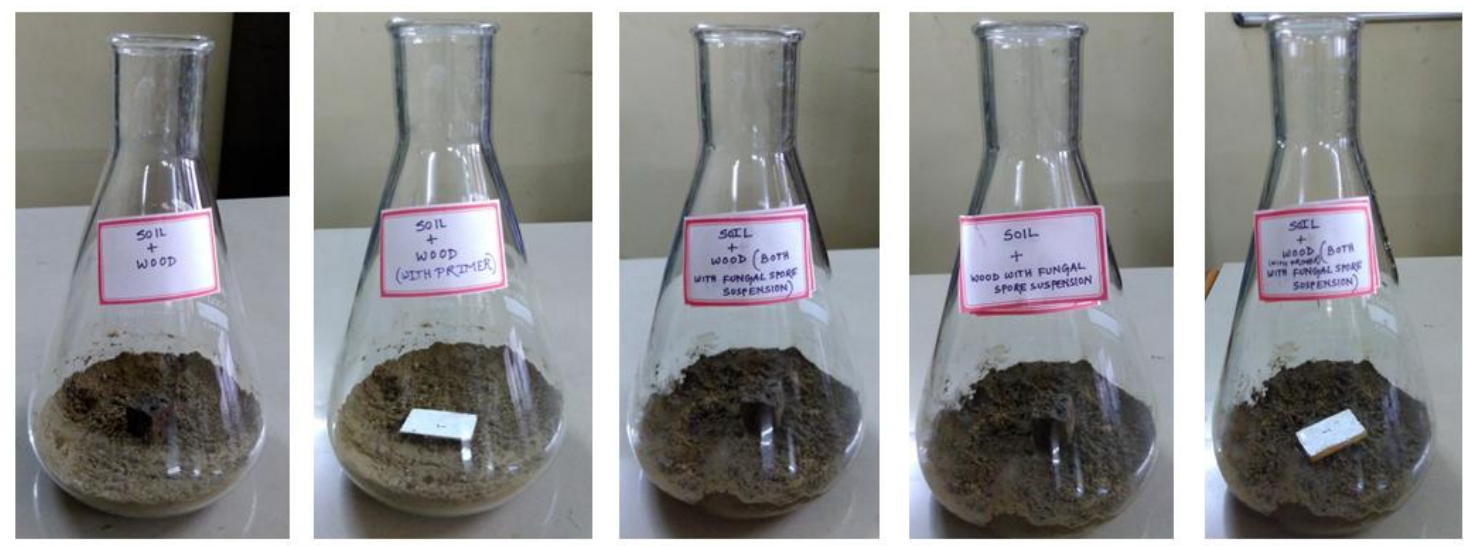

Figure 8: Experimental set up for the Soil jar experiment in presence or absence of primer: (A) Control (B) Soil Sample+ Infected wood in presence of primer (C) Soil+ Infected wood sprayed with fungal spore suspension (D) Both soil and infected wood sprayed with fungal spore suspension without primer (E) Both soil and infected wood sprayed with fungal spore suspension in presence of primer.

\section{Conclusion and Discussion}

Wood is still widely used as a construction material in building but in spite of great assortment of antifungal chemicals, incidents of treated-wood damage still happen. The mycological damage of treated wooden constructions and finishing details caused by fungi (wood rot, moulds and "blue staining") may result in great economical losses, lower product quality and even endanger human health indoors. Soft rot is considered to be the first decay stage found in a general sequence of wood colonization. It caused by fungi from the Ascomycota and Deuteromycota. Cylindrical cavities within secondary cell walls or cell wall erosion are formed after lignocellulose matrix in wood attack by fungal enzymes. Though it's a shallow wood damage and it cause insignificant mass loss (7\% - 8\% in 30 month in Scots pine) compared with brown- and white rot but even these few percents can drastically decrease the impact bending strength. Ceriporiopsis subvermispora is one of the best examples of a selective lignin degrader produces oxidative enzymes during wood biodegradation [7]. Rotten wood has a lower density, worse mechanical properties and its physical properties are changed individually according to the kind of rot (brown, white or soft) [8]. The ability of soft rot fungi to adapt to various environmental conditions and their physiological properties causes difficulties in searching means against wood damage. Soft rot fungi can be found even in dry environments and are mostly known to occur where brown- and white-rot are inhibited by factors such as high moisture content, low aeration and presence of preservatives or high temperatures Traditional wood protection methods involve treating with synthetic chemicals composed with aromatic compounds or heavy metals. Wood and other lignocellulosic materials are formed from three main polymeric constituents: cellulose, lignin, and hemicelluloses [9]. It was reported that many wood rotting fungus plays an important role in the biodegradation of polycyclic hydrocarbons (PAHs) [10]. There are reports that oxalic acid produced by fungi presumably precipitates copper into insoluble form of the oxalate, rendering the copper metabolite inert. Other ways of fungal self-protection involves extracellular mucilaginous material that acts as a protective layer surrounding the organism, fungal ability to absorb different metal ion amounts into cell wall and other intercellular structures. Due to the unspecificity of ligninolytic extracellular enzymes (phenoloxidases) some of fungi can degrade not only lignin but some aromatic compounds that are used in wood protection (e.g. pentachlorophenol) as well [4]. They produce volatile compounds and/or mycotoxins as well as spores themselves that could raise significant human health danger (allergic, respiratory diseases) resulting from their inhalation. Taking into account all the above mentioned soft rot fungal significance, the studies of their properties are of extreme importance. It is necessary to develop a better database on the fungal diversity on treated wood as well as investigate their physiological-biological properties. For that purpose fungal isolates from treated wood were identified and their ligninolytic and cellulolytic activities, medium acidification ability and sensitivity for antifungal chemicals were estimated. In our study we concluded that primer is not completely effective in protecting wood from environmental and biological hazards but in presence of primer the degradation of wood is reduced to a certain extent.

\section{Acknowledgements}

Financial support and constant guidance from Dr. Arup Kumar Mitra is gratefully acknowledged. Suggesations and help with biochemical analysis from Dr. Sudeshna Shyam Choudhury is greatly acknowledged. We would 
like to thank "Kurseong Botanical Garden" authority for allowing us to collect samples for our project. Thanks also to Pintu Biswas for his help in spectrophotometric analysis.

\section{References}

[1]. Robert A. Blanchette, Degradation of the Lignocellulose Complex in Wood, Canadian Journal of Botany 73(Suppl.1) 1995: pp. S999 - S1010. http://dx.doi.org/10.1139/b95-350

[2]. A. Pornou , E. Bogomolova , Fungal Colonization on Excavated Prehistoric Wood: Implications for in-situ display, International Biodeterioration and Biodegradation 63(4) 2009: pp. 371 - 378.

[3]. D. Kluepfel, Screening of Prokaryotes Cellulose- and Hemicellulose-degrading Enzymes , Methods in Enzymology, Elsevier Inc. 1601988 , pp. $180-186$.

[4]. A. D Bholay, BV Borkhataria, PU Jadhav, Bacterial Lignin Peroxidase: A Tool for Biobleaching and Biodegradation of Industrial Effluents, Universal Journal of Environmental Research and Technology, Volume 2, Issue 1: 58-64

[5]. M. del Pilar Castillo, P. Ander \& J. Stenstrom (1997), Lignin \& Manganese Peroxidase activity in extracts from straw solid substrate fermentations. Biotechnol. Techn, 11(9), 701-706.

[6]. Danguolè Bridziuviene ,Vita Raudoniene, Fungi Surviving on Treated Wood and Some of Their Physiological Properties. ISSN 1392-1320, Materials science (medžiagotyra), Vol. 19(1), 2013.

[7]. Hiromi Tanaka, Kenji Koike, Shuji Itakura, Akio Enoki, Degradation of wood and enzyme production by Ceriporiopsis subvermispora, Enzyme and Microbial technology, Elsevier Inc. 45(5), 2009

[8]. Ladislav Reinprecht, Helena Novotna, Vilem Stefka, Density profiles of spruce wood changed by brown rot and white rot fungi, Wood Research, 52 (4), 17-28, 2007

[9]. Catherine G. Duncan, Flora J. Deverall, Degradation of Wood Preservatives by Fungi, Applied and Environmental Microbiology; American Society for Microbiology, 12(1), 1964, (57-62)

[10]. Oliver Potin , Etienne Veignne , Catherine Rafin (2004): Biodegradation of polycyclic aromatic hydrocarbons (PAHs) by Cladosporium sphaerospermum isolated from an aged PAH contaminated soil , FEMS Microbiology Ecology 51(1), 2004, (71-78) 